\title{
Design and Performance Study of Clutch Disc Assembly of Wide-Angle, Large-Hysteresis, Multistage Damper
}

\author{
Maoqing Xie ${ }^{1,2}$, Leigang Wang ${ }^{1 *}$ (D) and Yao Huang ${ }^{1}$
}

\begin{abstract}
The clutch is an important component of the vehicle driveline system. One of its major functions is to attenuate or eliminate the torsional vibration and noise of the driveline system caused by the engine. Based on experiments of vibration damping under different vehicle conditions, the structure and functional principle of a clutch-driven disc assembly for a wide-angle, large-hysteresis, multistage damper is investigated in this study using an innovative combined approach. Furthermore, a systematic integration of key technologies, including wide-angle low-stiffness damping technology, large-hysteresis clutch technology, a novel split pre-damping structure technology, damping structure technology for component cushioning, and multistage damping structure technology, is proposed. The results show that the total torsional angle of the wide-angle large-hysteresis, multistage damper is more than twice that of the traditional clutch damper. The multistage damping design allows a better consideration of various damping requirements under different vehicle conditions, which can effectively address problems of severe idle vibrations and torsional resonance that occur under idled and accelerated conditions. Meanwhile, the use of a large-hysteresis structure and wear-resistant materials not only improves the vibration damping performance, but also prolongs the product service life, consequently resulting in multi-faceted optimization and innovative products.
\end{abstract}

Keywords: Clutch, Noise, Vibration, Wide angle, Low stiffness, Large-hysteresis, Multistage damper

\section{Introduction}

In China, factors such as the sustainable growth of automobile production, increase in vehicle ownership, and expanding demand in the export market, promoted the development of the automobile clutch industry. Noise, vibration, and harshness (NVH), which constitute rigid indicators for evaluating the vehicle performance [1], is a major factor to consider during automobile purchase [2, 3]. The power transmission system, which is an important component in automobiles, is the primary source of most noise problems, and its vibration contributes primarily to the vibration of the entire vehicle $[4,5]$. Therefore,

\footnotetext{
${ }^{*}$ Correspondence: Igwang@ujs.edu.cn

${ }^{1}$ School of Materials Science and Engineering, Jiangsu University, Zhenjiang 21200, China

Full list of author information is available at the end of the article
}

automobile manufacturers and users place high emphasis on the vibration problem occurring in the vehicle transmission system [6-8]. Torsional vibration in the vehicle driveline not only aggravates the load of driveline components such as shafts, bearings, gears, and shells, but also increases noise inside the vehicle, which can consequently degrade driving comfort [9-11]. In most cases, a torsional damper is arranged on the clutch-driven disc assembly for attenuating or reducing the vibration and noise of the vehicle driveline system. The elastic element of the damper can reduce the torsional stiffness of the driveline system, whereas its damping element enables the attenuation of torsional vibration energy in the system, consequently reducing the system natural frequency and attenuation of torsional vibration [12-14].

Research pertaining to vehicle-driveline torsion began early abroad and is profound. By optimizing the damping 
torque of a torsional damper, Prasad et al. [15] reduced the fluctuation amplitude of driveline torsion, thereby reducing the gear rattle noise under vehicle driving conditions. Focusing on the gear rattle problem under an idle operation, Tsujiuchi et al. [16] analyzed the effect of firststage hysteresis torque of a torsional damper on the rattle intensity and selected the optimal magnitude of hysteresis torque based on simulation results. By performing the torsional vibration modeling of the vehicle driveline system, Bhagate et al. [17] reduced the torsional fluctuation amplitude and gear rattle intensity of the driveline. In addition, they selected the optimal torsional stiffness and retarding torque for the damper through experimental design.

Domestic studies pertaining to driveline torsion began late. To address the severe transmission gear rattle problem that occurs in the vehicle crawling condition, Wu et al. [18] designed and developed a novel three-stage stiffness torsional damper and verified its performance through special bench and real vehicle tests. Liu et al. [19] proposed a four-degree-of-freedom lumped parameter modeling for the vehicle driveline system in the idle state and presented a method for computing the system dynamic response under an idle operation.

In recent years, more comprehensive investigations have been performed to understand vibration problems in transmission systems based on previous studies. In Ref. [20], a general torsional vibration model of vehicle powertrains was created, with which the effect of coupling stiffness on the powertrain dynamic behavior was analyzed comprehensively. Furthermore, a theoretical model and a program for dynamic optimization were constructed based on the genetic algorithm, thereby enabling an effective attenuation of the system torsional vibration. A one-dimensional multibody mathematical model of torsional vibration was developed for front-wheel drivetrains, with which the flywheel inertia, transmission shaft stiffness, and clutch stiffness were optimized [21]. Through mathematical modeling and optimization, the drive system NVH was successfully reduced. In Ref. [22], an analytical model presenting the dynamic characteristics of the driveline system was developed for friction clutch engagement. By investigating the effects of torsional stiffness (clutch-driven disc assembly) and axial stiffness (cushion plate) on the initial jitter, it was discovered that the initial jitter can be improved effectively by appropriately increasing the disc assembly's torsional stiffness and reducing the cushion plate's axial stiffness.

Vehicle powertrain systems are a type of complex multiple-degree-of-freedom mechanical system comprising multiple subsystems and numerous components, where not all the rotation center lines of the components are on the same plane [23-25]. During vehicle driving, factors such as fluctuations in the engine output torque, unbalanced engine crankshaft mass, road surface excitation, impact during clutch disengagement and engagement, and gear drive rattle can cause vibration in vehicle driveline systems [26-28]. Hence, the vibration problems of vehicle driveline systems caused by intrinsic structural complexity and multiple excitation sources are complicated $[29,30]$.

For traditional clutches, the ultimate torsional angle is difficult to enlarge owing to spatial and structural constraints, particularly in terms of the allowable stress of torsion springs and the spatial arrangement of limit pins; as such, higher torsional stiffness and undesirable damping effects are generated. Additionally, owing to the material strength and wear resistance, achieving significant damping is often difficult. In traditional clutch development, it is challenging to realize lower stiffness, reasonable large damping performance, and optimally combined damper parameters by surpassing the constraints of clutch-related space and material. Hence, a novel clutch torsional damper that can significantly improve the damping performance of traditional clutches was investigated in this study. (1) It achieves wide-angle, low-stiffness damping without increasing the specifications and torque transmission capacity. (2) It achieves large-hysteresis vibration damping while ensuring a long clutch service life. (3) It overcomes the shortcomings of traditional split pre-damping structures such as complex structure, multiple components, difficult assembly, low efficiency, and high manufacturing cost, thereby optimizing the design of split pre-damping structures and hence improving the production efficiency and reducing the manufacturing costs. (4) The design of the damping structure is optimized to reduce engine impact damage to the clutch components. (5) Multistage vibration reduction is achieved without increasing the damper specifications, thereby conforming to the $\mathrm{NVH}$ requirements of engines and vehicles under different operating modes.

\section{Structure and Operating Principle of Torsional Damper for Traditional Clutch-Driven Disc Assembly}

As shown in Figure 1, the structure of the traditional clutch-driven disc assembly primarily comprises friction facing, driven disc, retain plate, springs, and disc hubs. Engine power is transmitted to the clutch cover assembly via the flywheel. Subsequently, power is transmitted from the cover assembly to the driven disc (6) and retain plate (7) via the friction facing (1), and then to the disc hub (15) via the springs (17 and 18) for vibration damping. Eventually, power is transmitted from the disc hub (15) to the gearbox input shaft through the spline. For the traditional clutch-driven disc assembly, the torsional 


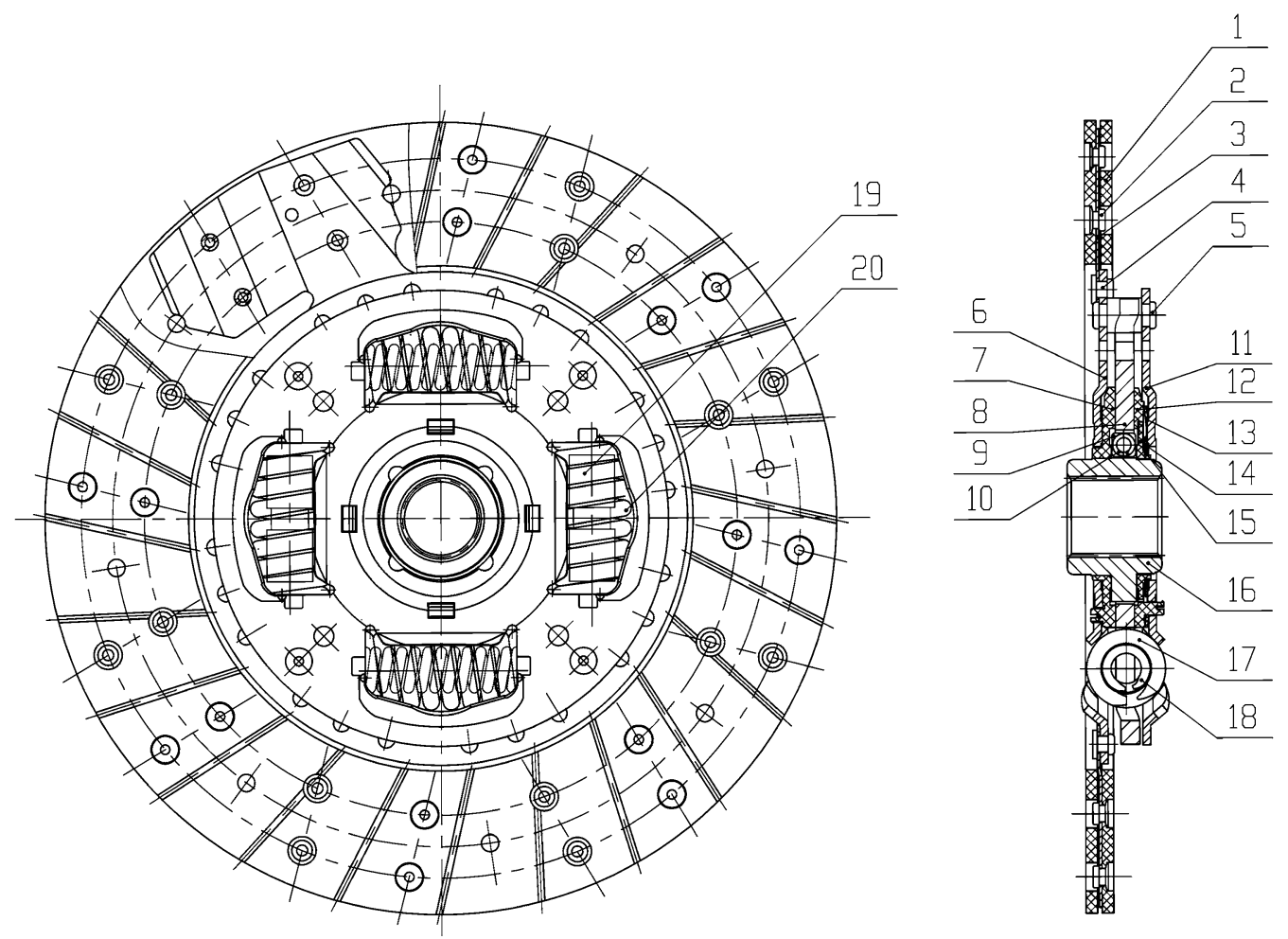

Figure 1 Diagram of traditional clutch-driven disc assembly. 1. Friction facing, 2. Friction facing rivet, 3. Cushion segment, 4. Cushion segment rivet, 5. Stop pin, 6. Driven disc liner, 7. Retain plate, 8. Positioning ring, 9. Belleville washer, 10. Positioning ring, 11. Belleville washer, 12. Positioning ring, 13. Spring seat, 14. Spring, 15. Disc hub, 16. Disc hub, 17. Spring, 18. Spring, 19. Rubber spring, 20. Spring

damper primarily comprises an idle damping system and a main damping system.

(1) Figure 2 shows the structure of an idle damping system for the traditional clutch illustrated in Figure 1.

The idle damping system comprises a positioning ring (8), Belleville washer (9), positioning ring (10), Belleville washer (11), positioning ring (12), spring seat (13), spring (14), disc hub (15), etc. The magnitude of the idle damping torque depends on the quantity and stiffness of the springs. By matching two types of springs with different stiffness values, 12 options of idle damping stiffness were derived, with a coverage range of up to $0.5-9 \mathrm{~N} \cdot \mathrm{m} /\left(^{\circ}\right)$, which satisfies the current vehicle requirements on idle damping stiffness. Upon the relative rotation of the inner spline hub (15) and outer disc hub (16) (see Figure 1) to the extreme positions, the splined side surfaces of the two were in contact, and the clutch entered the main damping mode.

(2) Figure 3 shows the structure of the main damping system for the traditional clutch illustrated in Figure 1.
The main damping system includes a stop pin (5), driven disc (6), retain plate (7), positioning ring (8), Belleville washer (9), positioning ring (12), disk hub (16), and springs (17 and 18). When the main damping system was operated, the primary damping spring installed on a window of identical width was initially compressed. After the relative rotation of the driven disc and retain plate to certain angles, the side of slightly wider driven disc window began to contact the secondary damping spring. All the damping springs were operating to alleviate the impact generated during clutch engagement and power transmission. Owing to the action of the Belleville washer during the relative rotation between the driven disc and retain plate, the damping washer generated a certain frictional damping torque with the driven disc and retain plate for vibration attenuation. The stiffness of the main damping system and the magnitude of the main damping torque depended primarily on the stiffness and ultimate load of the main damping springs, whose design basis was the matching requirements of the entire vehicle driveline system. Main damping springs of different stiffness and ultimate loads were designed, and they served as a standard series with 

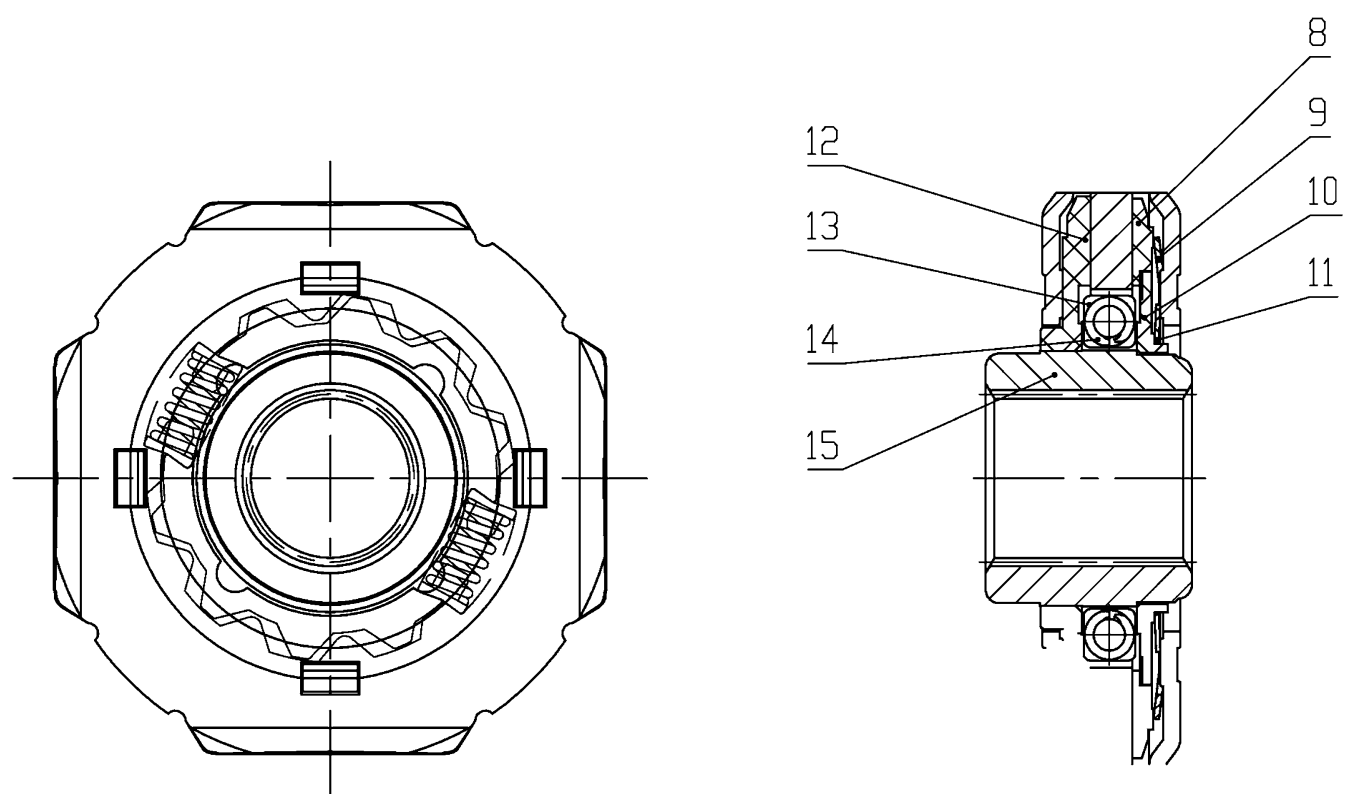

Figure 2 Diagram of idle damping system of traditional clutch-driven disc assembly. 8. Positioning ring, 9. Belleville washer, 10. Positioning ring, 11. Belleville washer, 12. Positioning ring, 13. Spring seat, 14. Spring, 15. Disc hub
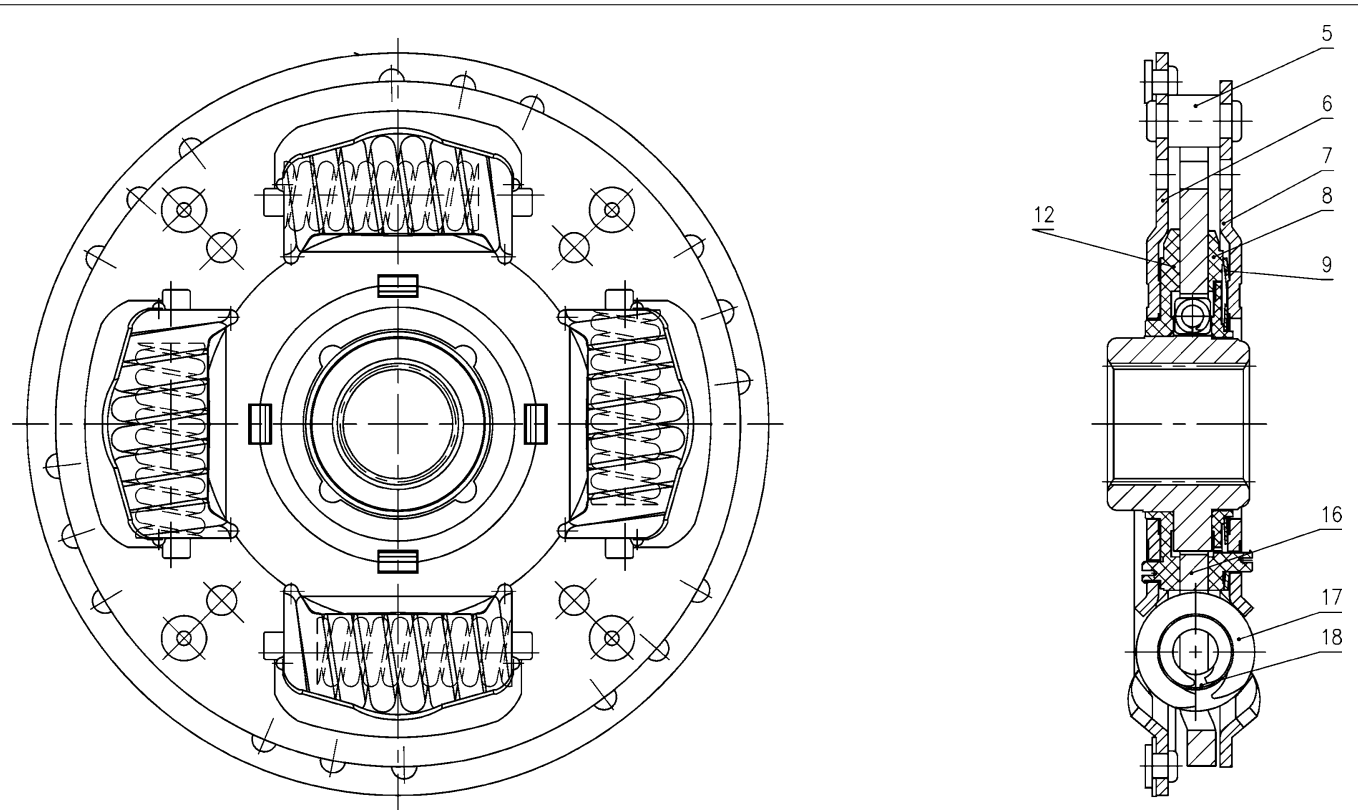

Figure 3 Diagram of main damping system of traditional clutch-driven disc assembly. 5. Stop pin, 6. Driven disc, 7. Retain plate, 8. Positioning ring, 9. Belleville washer, 12. Positioning ring, 16. Disc hub, 17. Spring, 18. Spring

identical external dimensions. Constrained by the ultimate material stress, some springs could not function in the compressed state. At this point, the stop pin (5) will protect the main damping spring to a certain extent by contacting the corresponding notch side of the disk hub (16).

In general, the entire vehicle's NVH characteristics were improved through the clutch by adjusting the 
structure of the driven disc and altering its performance parameters, where the critical step was the adjustment of elastic and damping elements. The main performance parameters involved were the ultimate torque $T$ (torque transmission capacity), torsional stiffness $K$, torsional angle $\theta$, and hysteresis value $H$, which are correlated as follows:

$$
T=K \theta+H=\beta T_{e},
$$

where $T_{e}$ denotes the maximum output torque of the engine. As an inherent characteristic of the engine, its value is fixed. $\beta$ signifies the reserve coefficient of the clutch and is a constant. Generally, $\beta$ is assigned as 1.3 and 1.6 for passenger and commercial vehicles, respectively.

An analysis of the torsional mode and sensitivity for the driveline system by Bi et al. [31, 32] indicated that the torsional stiffness $K$ and hysteresis $H$ of the clutch were two major determinants of the damping function for the driven disc. A lower torsional stiffness results in a lower resonance peak value and hence a lower resonance frequency. A larger hysteresis results in a lower resonance peak value, while the resonance frequency changes insignificantly. Hence, to dampen the vibration transmitted by the engine as quickly as possible, the torsional stiffness of clutch-driven disc should be minimized, whereas the hysteresis value should be maximized. Nevertheless, for the spatial and structural constraints of the main damping system, the traditional clutch has a relatively narrow torsional angle, a high spring torsional stiffness, and a narrow damping adjustment range. Additionally, the torsional angle of the traditional idle damping system is limited owing to the spatial and structural constraints, which can restrict the clutch damping performance significantly.

In summary, the $\mathrm{NVH}$ characteristics of the entire vehicle can be improved by reducing the torsional stiffness through torsional angle enlargement (wide angle), or by adequately increasing the hysteresis value. Therefore, a clutch-driven disc assembly of wide-angle, large-hysteresis, multistage dampers is proposed herein.

\section{Structure Design and Principle of Clutch-Driven Disc Assembly of Novel, Wide-Angle, Large-Hysteresis, Multistage Dampers}

Based on the theoretical analysis of torsional vibration, this study can be performed using the elastic and damping elements of the torsional damper to address the disadvantages of traditional clutches. After conducting the characteristics analysis of the clutch torsional damper, five key technologies are proposed, as follows: wide-angle low-stiffness damping technology, largehysteresis clutch technology, a novel split pre-damping structure technology, damping structure technology for component cushioning, and multi-stage damping structure technology. Through system integration and the optimal combination of these five key technologies, a wide-angle, large-hysteresis, multistage damper clutch assembly was developed.

The proposed clutch-driven disc assembly of the wideangle, large-hysteresis, multistage damper comprised a front retain plate, rear retain plate, hub plate, damping spring, cushioning spring, rear hysteresis plate, front hysteresis plate, and Belleville washer; its structure is presented in Figure 4.

The technologically innovative traits of the proposed clutch-driven disc assembly are as follows.

(1) Wide-angle, low-stiffness damping technology

Reduced spring stiffness can be achieved by widening the torsional angle of the clutch without increasing the specifications and torque transmission capacity of the damper such that the clutch yields better damping performance. Because the main damping component of the traditional clutch is limited by the stop pin (double-headed rivet) impacting the hub (Figure 5), its rotation angle could not be widened owing to the spatial constraints (the rotation angle is generally $\left.7^{\circ}-15^{\circ}\right)$. Hence, a new design is proposed to bend the outer side of the front retain plate and replace the brake pin, which is an impactlimiting component, using the retain plate (as shown in Figure 6).

Traditional clutches generally have forward torsional angles of $15^{\circ}-21^{\circ}$ and reverse torsional angles of $10^{\circ}-15^{\circ}$, as presented in Figure 7. By contrast, owing to the wide-angle clutch solution, the forward and reverse torsional angles can reach $42^{\circ}$ and $28^{\circ}$, respectively, as shown in Figure 8, revealing the improvement in the damping effect by more than 1.5 folds. Moreover, within an 800-4500 r/min engine range, its vibration isolation rate can exceed $65 \%$.

(2) Large-hysteresis damping structure technology

To obtain the optimal hysteresis, the hysteresis values of the main damper and pre-damper are adjusted using the Belleville washer forces, damping washer material, and number of friction pairs. Meanwhile, the force values of Belleville washers are adjusted using the thickness and forming angle of the material. The damping washer comprises an iron component and a plastic component. The iron gasket, 

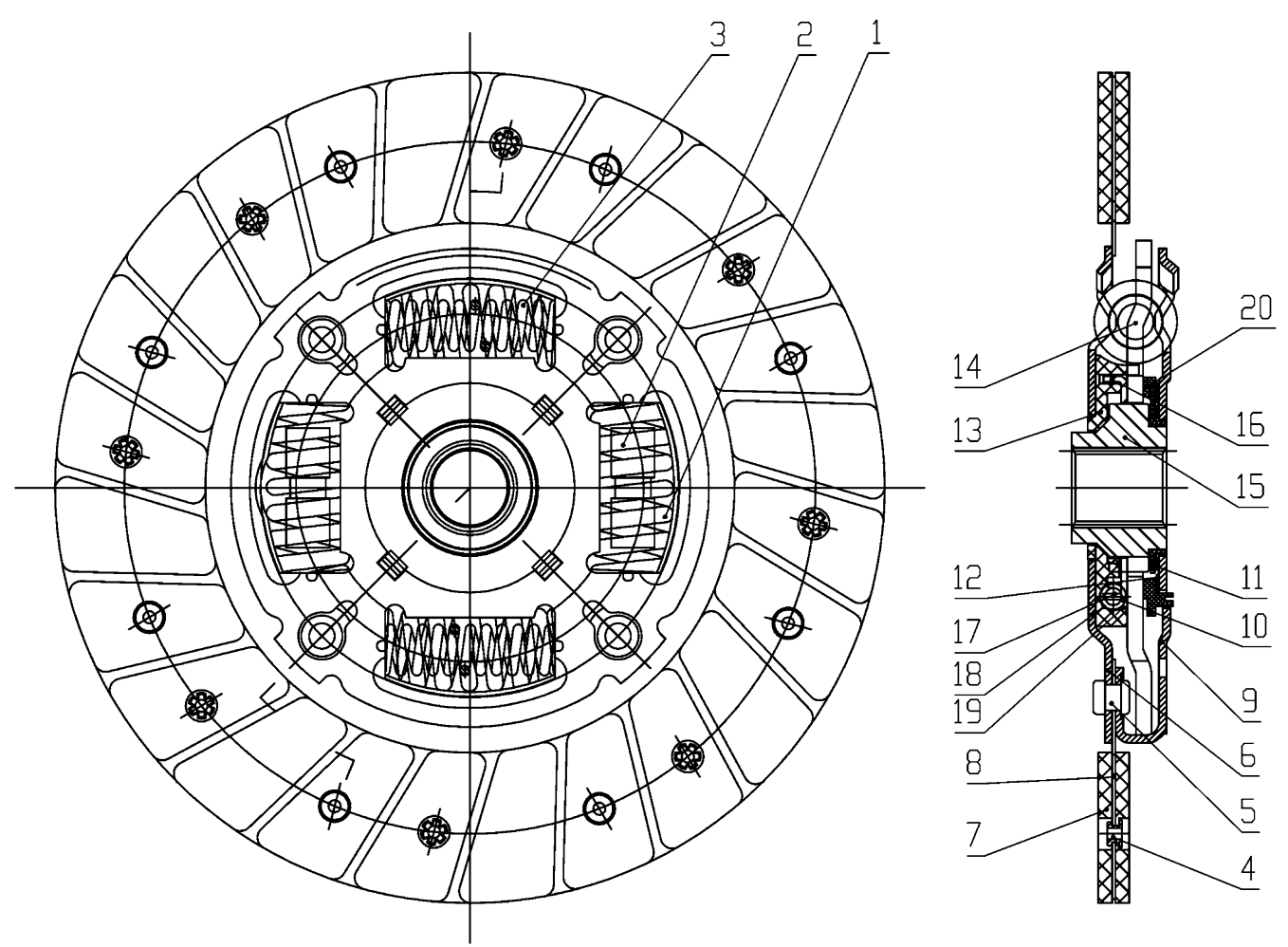

Figure 4 Diagram of clutch-driven disc assembly for wide-angle, large-hysteresis, multistage damper. 1. Main damping spring (outer), 2. Rubber cushioning spring, 3. Main damping spring (inner), 4. Friction facing rivet, 5. Retain plate rivet, 6. Rear retain plate, 7. Friction facing, 8. Cushion plate, 9. Front retain plate, 10. Pre-damping Belleville washer, 11. Pre-damping hysteresis plate, 12. Main damping Belleville washer, 13. Main damping plate, 14. Hub plate, 15. Hub 16. Pre-damping hub plate, 17. Primary pre-damping spring, 18. Cushioning rubber pad, 19. Secondary pre-damping spring, 20. Rear hysteresis plate
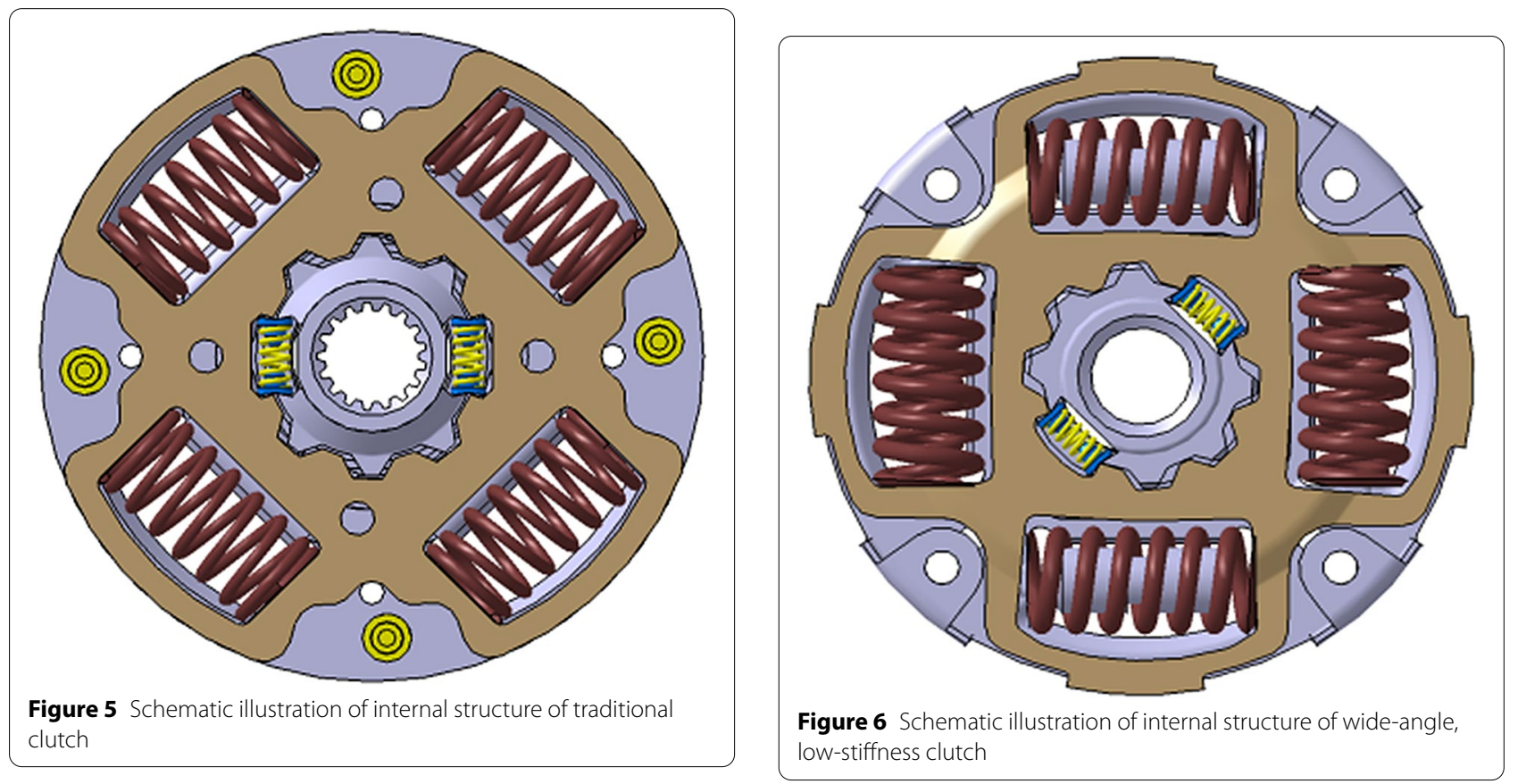


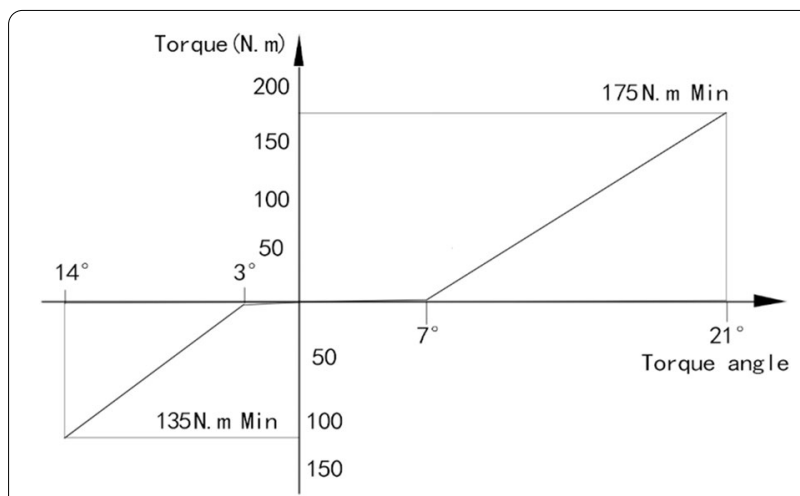

Figure 7 Graph showing torsion performance of traditional clutch

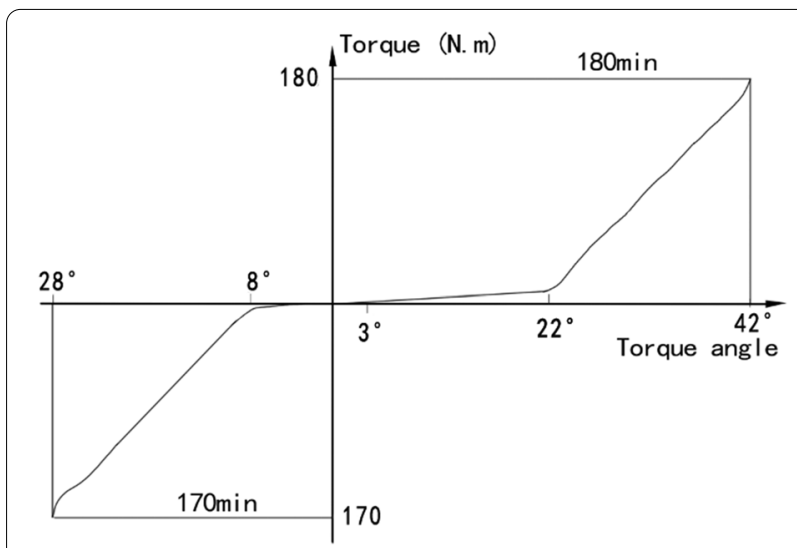

Figure 8 Graph showing torsion performance of wide-angle low-stiffness clutch

which is resistant to high temperatures and wear, has a small hysteresis. Meanwhile, although the plastic gasket is less resistant to high temperatures and wear than the iron gasket, it has a large hysteresis and can be designed into a complicated shape. The torque fluctuation during engine operation is consumed by optimizing the clutch hysteresis, which reduces the transmission of engine pulsating vibration by the clutch and reduces the vehicle jitter and gear rattle noise within the entire speed range induced by the vibrations of the gearbox, differential, and other driveline components under idled, accelerated, and normal driving conditions, consequently improving the driving comfort.

A large-hysteresis clutch exhibits a main damping hysteresis of $25-35 \mathrm{~N} \cdot \mathrm{m}$, whereas that of the traditional clutch is generally $8-15 \mathrm{~N} \cdot \mathrm{m}$. The predamping hysteresis is $1.5-2 \mathrm{~N} \cdot \mathrm{m}$ for a large-hysteresis clutch, whereas the corresponding hysteresis value for the traditional clutch is generally $1 \mathrm{~N} \cdot \mathrm{m}$. $\mathrm{NVH}$ testing was performed on a vehicle model of an independent brand using a Müller-BBM vehicle torsional vibration/noise measurement and analysis system (Figure 9). As shown in the experimental verification, the amplitude of the primary-order angular acceleration of the system can be reduced by increasing the hysteresis value of the clutchdriven disc, which can improve the NVH problem encountered during vehicle acceleration, as shown in Figure 10, where the first axle represents the primary-order angular acceleration output by the engine, and the input shaft is the primary-order angular acceleration of the gearbox input shaft after the torsional vibration is attenuated using a largehysteresis clutch.

(3) Novel split pre-damping structure technology

A novel split pre-damping structure (Figure 11), which optimized the space of the clutch damping system and enhanced the intensity of the idle damping system, was developed. Compared with the traditional structure (Figure 2), the developed split predamper comprised a pre-damping spring (1), rubber pad (2), rear hysteresis plate (3), pre-damping hub plate (4), and hub (5), where the traditional hysteresis plate was modified significantly such that it can function as both a hysteresis plate and a clamping plate. This not only widens the adjustment range of the frictional torque for the idle damper, but also addresses the disadvantages of the traditional split pre-damping structure, such as complex structure, multiple components, difficult assembly, low efficiency, and high manufacturing cost. Additionally, a large angle and arc design was adopted for the springs, allowing a wider range of torsional stiffness adjustment for the idle damper. When the torsional stiffness is excessively low, the idle damping spring will not function because of the damping torque; hence, secondary damping will be directly initiated. Consequently, an optimal idle torsional stiffness is required for the resistance torque of the gearbox, whose value is generally $0.1-0.6 \mathrm{~N} \cdot \mathrm{m} /\left(^{\circ}\right)$. In addition, the traditional clutch pre-damping structure often has a forward torsional angle of $3^{\circ}-8^{\circ}$ and a reverse torsional angle of $0^{\circ}-5^{\circ}$, as shown in Figure 7 . By contrast, the wide-angle clutch pre-damping structure can have forward and reverse torsional angles of up to $22^{\circ}$ and $8^{\circ}$, respectively, as shown in Figure 8. Hence, its damping effect is more than twice better than that of the ordinary clutch, and its 


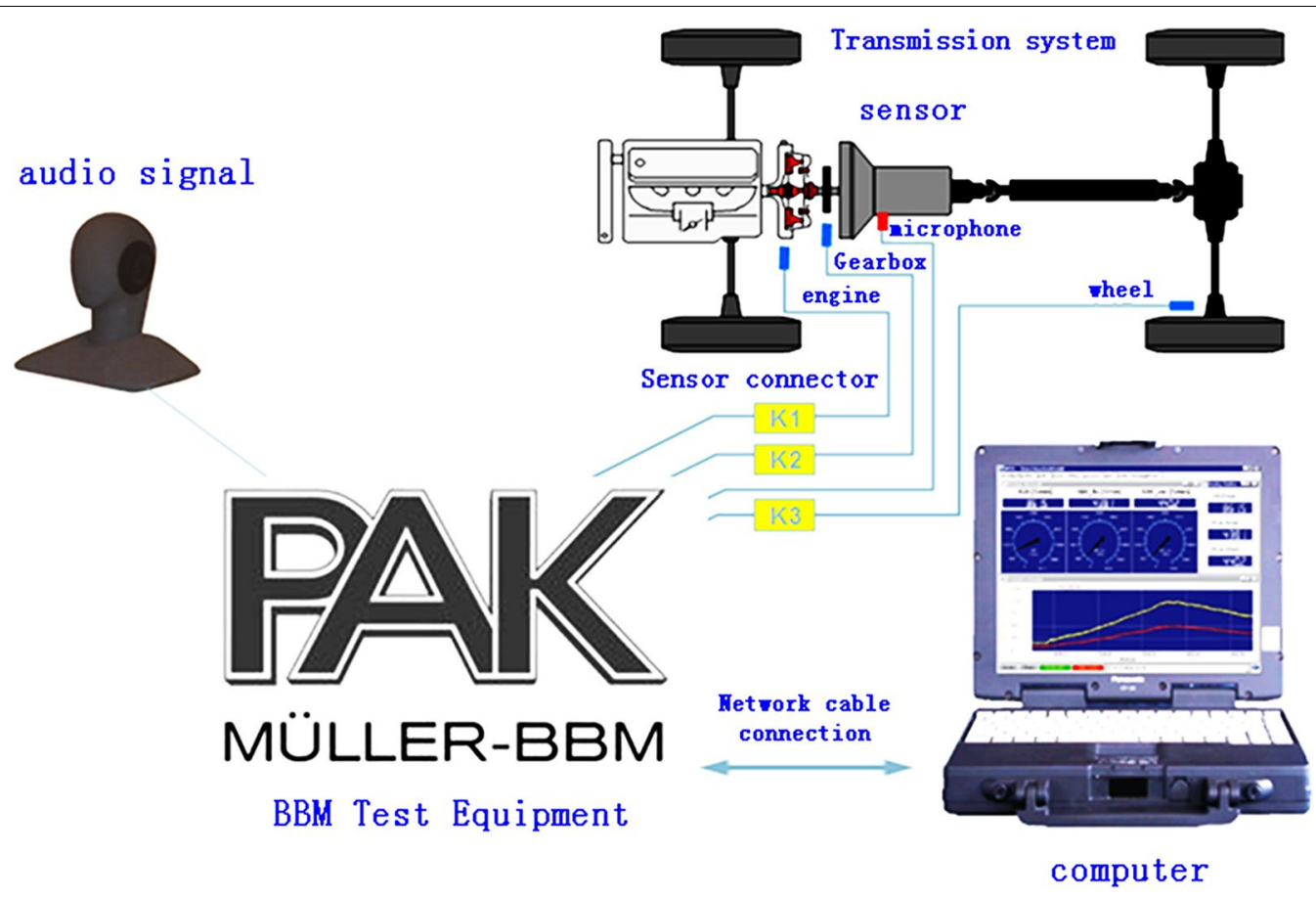

Figure 9 Torsional vibration/noise measurement and analysis system

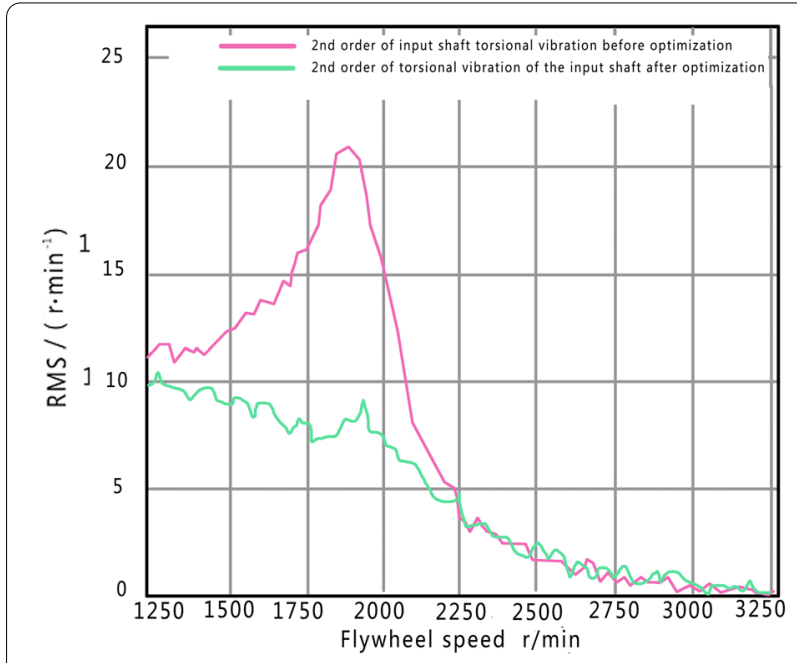

Figure 10 Attenuation test results of three-gear acceleration torsional vibration

vibration isolation rate can exceed $60 \%$ within an engine idle speed of $600-1200 \mathrm{r} / \mathrm{min}$.

(4) Damping structure technology for component cushioning

In the traditional damper, vibration damping and cushioning are achieved primarily via the inter- nal damping springs. However, upon reception of a large impact, the impact is entirely borne by the clutch stop pin (limiting rivet), thereby affecting the service life of the clutch, despite the clutch possessing certain damping and cushioning capabilities. The damping structure technology for component cushioning was adopted in this study, where two special rubber springs (Figure 12) were installed inside a symmetrical set of main damping springs. Upon the impact of the clutch, the installed springs absorbed the vibration and reduced noise while protecting the internal clutch components, thereby prolonging the service life of the clutch-driven disc assembly. They operated based on the following principles: After rubber springs were installed inside the damping springs, the latter part of the torsional damping characteristic curve increased progressively, as shown by the clutch characteristic curve in Figure 8. This is attributed to the cushioning action of the rubber springs, which alleviated the impact generated by the engine torque fluctuation and hence increased the clutch torque capacity. The rubber springs did not function during flatroad travel, and their torque transmission capacities were invariant. In a harsh road environment, the engine torque underwent significant fluctuations. At this time, the rubber springs began to operate, and their torque capacities increased by $15 \%$ imme- 

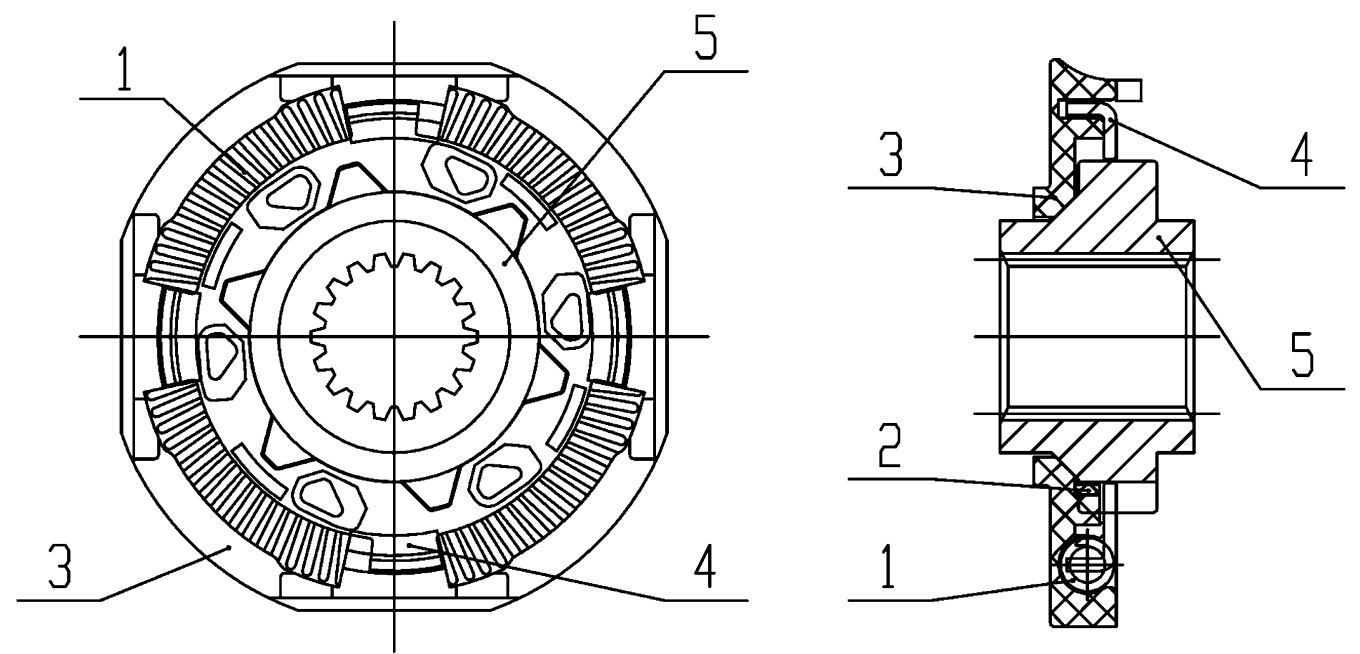

Figure 11 Schematic illustration of novel split pre-damping structure. 1. Pre-damping spring, 2. Rubber pad, 3. Rear hysteresis plate, 4. Pre-damping hub plate, 5. Hub
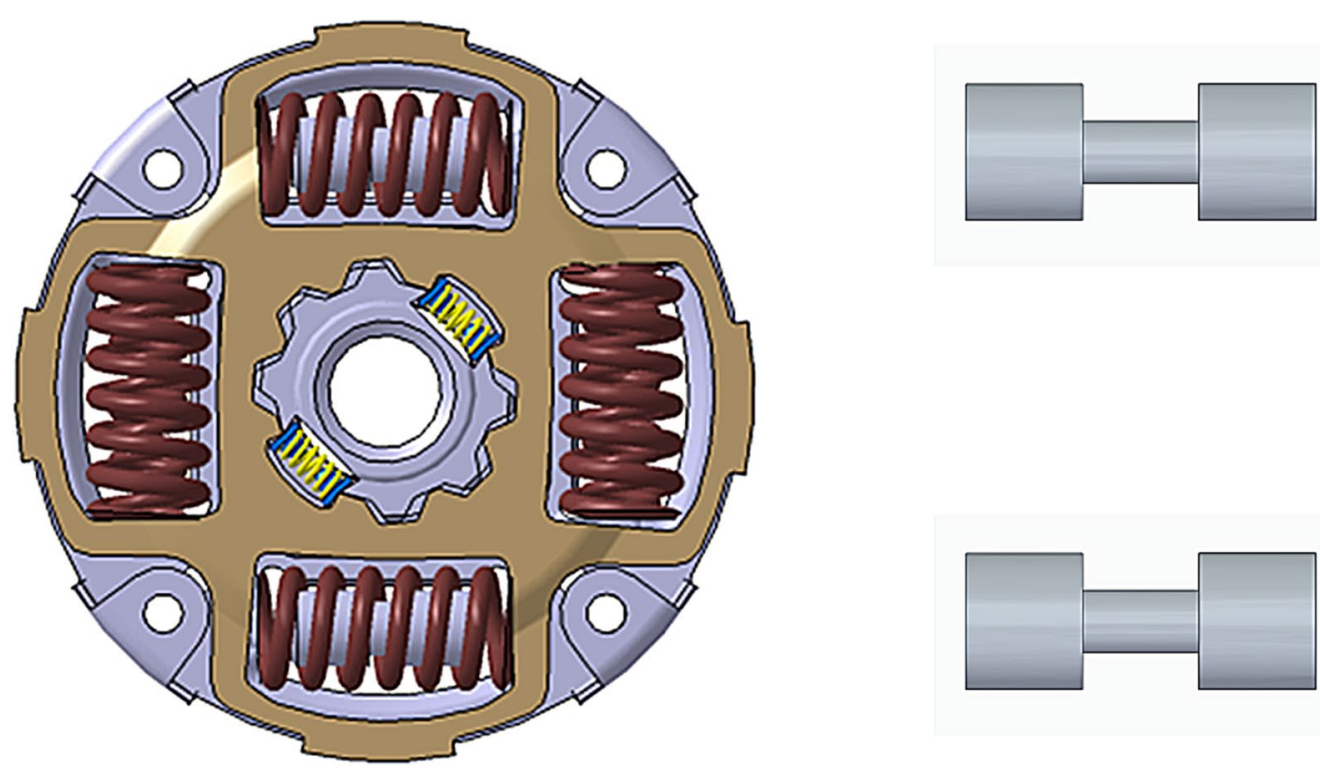

Figure 12 Diagram of rubber spring set (installed inside large springs)

diately, thereby protecting the internal components of the clutch and improving its fatigue life.

(5) Multistage damping technology

The power and torque output by the vehicle engine exhibit their respective characteristics under different operating conditions (such as idled, starting, accelerated, and constant speed driving). In general, the traditional clutch is provided with a mere level 1-2 damping, as shown in Figure 7, which can only satisfy the damping requirements under operating conditions 1-2. By contrast, the multistage damping technology involves the innovative use of a damping spring set that comprises various types of springs with different stiffness values. Using this spring set, a 3-6 multistage damping is achieved through a combination of clutch damping and predamping, which effectively adapt to the vehicle damping under various operating conditions. 
As shown by the clutch characteristic curve shown in Figure 7, the main damping and pre-damping systems of the traditional clutch generally have only one level each, which does not satisfy the damping requirements at different torques. By exploiting the asymmetry of the pre-damping hub plate, two-level pre-damping was achieved based on the difference in its plucking order of springs: Level 1 (forward 0-3 direction, reverse 0-3 direction) participates in the vibration damping in the idle state (minimum output power and torsion), whereas Level 2 (forward 3-22, reverse 0-32) participates in the vibration damping and torque transmission at the start (slightly higher output power and torsion). For the main damping system, a set of rubber springs is added inside the original damping springs, whose lengths are considerably shorter than those of the damping springs. These rubber springs begin to operate after the damping springs are compressed to a certain length owing to the clutch-transmitted torque. Additionally, they alleviated the impact generated by engine torque fluctuations and transmitted the torque. The main damping system (forward 22-42, reverse 8-282) adopts a two-level damping: Level 1 (forward 22-38, reverse 8-248) participates in the vibration damping during the constant velocity travelling of the vehicle (relatively stable output power and torsion; small torque waveform), whereas Level 2 (forward 38-42, reverse 24-28) is involved in the vibration damping and torque transmission during acceleration (maximum output power and torsion, large torque waveform, and accordingly the greatest impact on the clutch components).

\section{Performance Comparison between Novel and Traditional Torsional Damper Clutch Assemblies}

In this study, a clutch-driven disc assembly was developed for wide-angle, large-hysteresis, multistage dampers and was verified on a real vehicle.

(1) Comparison of main parameters with traditional clutch solution

Based on verification, the main performance parameters of the clutch product (Figure 4) developed by adopting the novel clutch-driven disc assembly technology of wide-angle, large-hysteresis, multistage dampers reached the internationally advanced levels of similar products. Table 1 shows a comparison of performances.

(2) Comparison of damping performance with traditional clutch solution

$\mathrm{NVH}$ testing was performed on a vehicle model of an independent brand (the same vehicle), which was equipped separately with the traditional and proposed clutch-driven disc assemblies. A MüllerBBM torsional vibration/noise measurement and analysis system was utilized during this real vehicle verification. Figures 13 and 14 show the test results.

Under the idle condition shown in Figure 13 (left image), the speed fluctuation was amplified after the transmission of the engine (flywheel) speed to the first shaft of the gearbox via the traditional clutch, and the vehicle was prone to jitter and rattle noise. By contrast, for the transmission via the

Table 1 Comparison of main parameters of current, foreign, similar technologies

\begin{tabular}{|c|c|c|c|c|}
\hline Test item & Performance parameter index & $\begin{array}{l}\text { Drawing technical } \\
\text { requirement }\end{array}$ & Performance of this product & $\begin{array}{l}\text { Performance of internationally } \\
\text { advanced products }\end{array}$ \\
\hline \multirow{4}{*}{$\begin{array}{l}\text { Static torque } \\
\text { character- } \\
\text { istics }\end{array}$} & Pre-damping torsional Angle $\left(^{\circ}\right)$ & $5-22$ & 21.82 & 16.72 \\
\hline & $\begin{array}{l}\text { Main damping Torsional angle } \\
\left({ }^{\circ}\right)\end{array}$ & $7-21$ & 20.21 & 15.76 \\
\hline & Main damping Hysteresis $(\mathrm{N} \cdot \mathrm{m})$ & $7-35$ & 32.37 & 25.63 \\
\hline & Forward torque $(\mathrm{N} \cdot \mathrm{m})$ & $190 \pm 20 \%$ & 198.72 & 189.78 \\
\hline Reliability test & Torque fatigue test & $\begin{array}{l}\text { No rupture or deformation of } \\
\text { components after } 1 \text { million } \\
\text { torsion tests at a maximum } \\
\text { engine torque under } 1.3 \\
\text { times loading }\end{array}$ & $\begin{array}{l}\text { No rupture or deformation of } \\
\text { components after } 3.5 \text { million } \\
\text { torsion tests }\end{array}$ & $\begin{array}{l}\text { No rupture or deformation of } \\
\text { components after } 1 \text { million } \\
\text { torsion tests }\end{array}$ \\
\hline
\end{tabular}



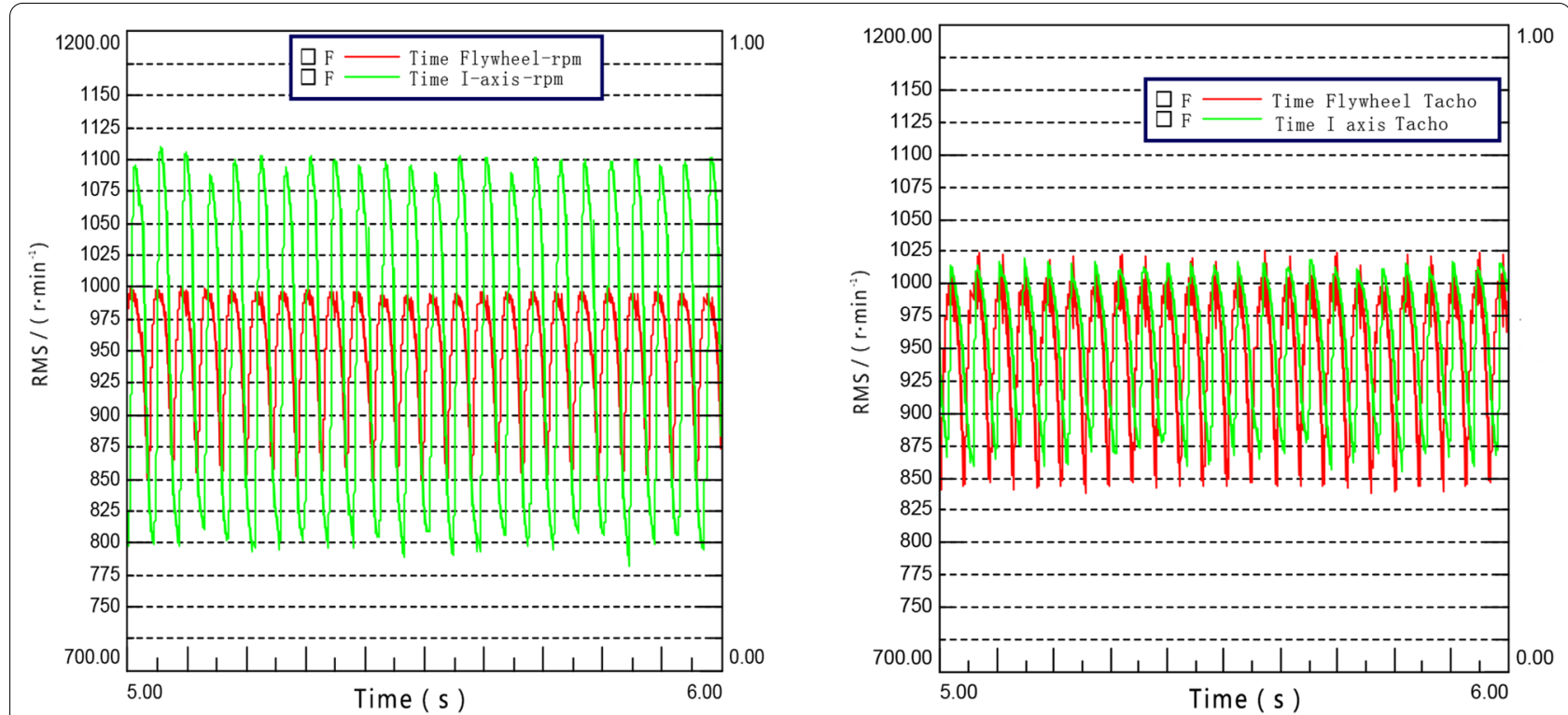

Figure 13 Flywheel and first shaft speed fluctuations under idle condition (left: traditional clutch; right: wide-angle, large-hysteresis, multistage damping clutch)
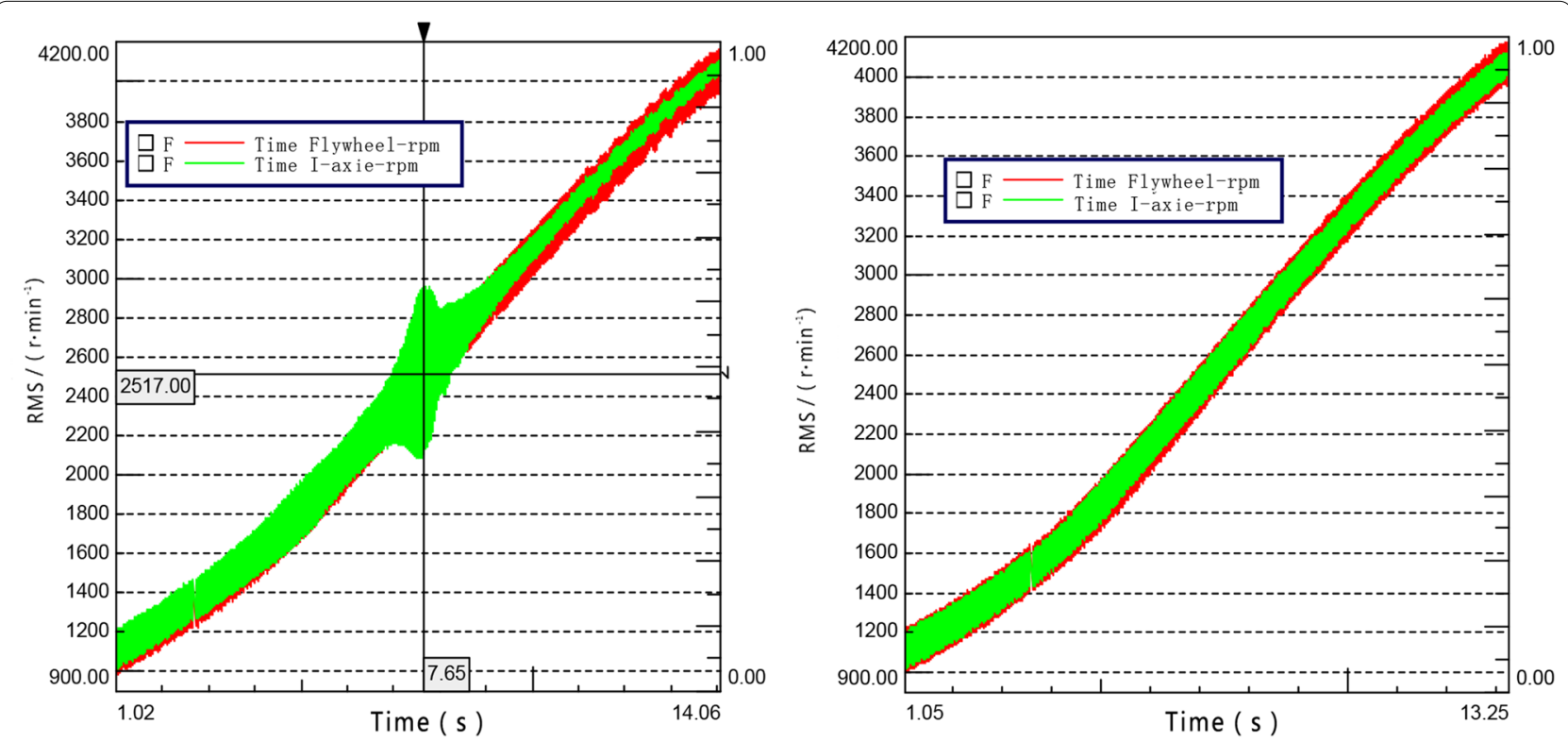

Figure 14 Flywheel and first shaft speed fluctuations under full acceleration in second gear (left: traditional clutch; right: wide-angle, large-hysteresis, multistage damping clutch)

novel clutch (right image), the speed fluctuation attenuated substantially, revealing a prominent damping effect of the clutch. Meanwhile, under a full acceleration in the second gear, as shown in Figure 14 (left image), the first shaft of the gearbox demonstrated resonance at the speed of approxi- mately $2738.94 \mathrm{r} / \mathrm{min}$ after it received the engine (flywheel) speed via the traditional clutch. By contrast, for the transmission via the novel clutch (right image), no apparent abrupt change in speed was detected. This suggests that the driveline system has no resonance within a speed range of 
1000-4500 $\mathrm{r} / \mathrm{min}$ (the typical engine speed range) under this gear stage, and the damping performance improved significantly.

\section{Conclusions}

(1) A wide-angle low-stiffness damping solution was proposed. Based on the clutch operating principle, the limiting device during damper operation improved. It exhibited a larger torsional angle and a lower stiffness to achieve the vibration damping effect. Compared with the traditional clutch, the torsional damping angles of the proposed main damper and pre-damper enlarged by more than two folds, thereby alleviating the torsional resonance and idling rattle noise of the driveline system and prolonging the service life of the driveline components.

(2) Large-hysteresis clutch technology was proposed, where a large hysteresis was achieved by improving the material and structure of the clutch damping system such that the clutch can withstand the hysteresis attenuation caused by a harsh wear environment. Additionally, the resonance amplitude of the vehicle driveline system can be reduced, thereby alleviating the noise problem during vehicle use.

(3) A novel split pre-damping structure technology, which easily realizes the complex modeling features of the workpiece via injection molding, was proposed. The traditional hysteresis plate was modified such that it functions as both a hysteresis plate and a clamping plate. This technology addresses the disadvantages of the traditional split pre-damping structure, including complex structure, multiple components, difficult assembly, low efficiency, and high manufacturing cost.

(4) A damping structure technology for component cushioning was proposed, where rubber cushioning springs were installed inside the damping springs of the traditional clutch; additionally, the buffer principle of rubber was exploited to absorb vibrations and reduce noise during an impact, while simultaneously protecting the internal components of the clutch. Using this technology, upon the significant fluctuation of the engine torque during vehicle travel under a harsh condition, the rubber springs began to operate, whose torque capacities increased immediately to absorb vibrations and reduce noise while protecting the internal clutch components, thereby prolonging the service life of the clutch.

(5) Multistage damping technology was proposed, in which a damping spring set comprising springs with different structures and stiffness values was used to upgrade the clutch damping from the original 1-2 stage damping to a 3-6 stage damping, thereby fulfilling the $\mathrm{NVH}$ performance requirements under various operating conditions.

The wide-angle, large-hysteresis, multistage damping clutch assembly series has been applied in the market and has garnered accolades owing to its superior performance. Therefore, the novel clutch damper is expected to be the basis for future clutch developments.

\section{Acknowledgements \\ Not applicable.}

\section{Authors' Contributions}

MX, methodology, investigation, validation, investigation, software, writingoriginal draft and writing-review \&editing. LW, technical guidance. YH, data collection, data analysis, data interpretation. All authors read and approved the final manuscript.

\section{Authors' Information}

Maoqing Xie, born in 1974, PhD candidate, Senior Engineer. His research interests include advanced manufacturing technology, new material technology, friction materials science and mold design and manufacturing.

Leigang Wang, born in 1963, Doctoral supervisor. His research interests include CAD/CAE/CAM of mold, plastic processing tribology, and material mechanics behavior computer simulation.

Yao Huang, born in 1964, Master supervisor. Her research interests include CAD/CAE/CAM of mold, plastic processing tribology, and material mechanics behavior computer simulation.

\section{Funding}

Supported by National Natural Science Foundation of China (Grant No. 51775249).

\section{Competing interests}

The authors declare that they have no competing interests.

\section{Author Details}

${ }^{1}$ School of Materials Science and Engineering, Jiangsu University, Zhenjiang 21200, China. ${ }^{2}$ Zhejiang Tieliu Clutch Co., Ltd., Yongkang 321300, China.

Received: 16 November 2020 Revised: 27 April 2021 Accepted: 13 May 2021

Published online: 31 May 2021

\section{References}

[1] G Q Wu, W B Luan. Reviews of dynamic research for NVH problems related to automotive driveline. Journal of Mechanical Engineering, 2013, 49(24): 108-116. (in Chinese)

[2] HWWu, G QWu. Driveline torsional analysis and clutch damper optimization for reducing gear rattle. Shock and Vibration, 2016, Article ID 8434625

[3] G Q Wu, HW Wu, X Chen. The nonlinear characteristics impact of multistaged stiffness clutch damper on the vehicle creeping. SAE, 2016-010431, 2016.

[4] HWWu, G QWu, X Chen, et al. Numerical and experimental analysis on multi-staged stiffness clutch dampers considering hysteresis characteristics. Journal of Vibration and Shock, 2017, 36(2): 170-176. (in Chinese)

[5] Q R Chen. Simulation analysis and experimental study of friction clutch vehicle starting vibration. Chengdu: Southwest Jiaotong University, 2017. (in Chinese) 
[6] Martinh, A Kooy, W Roland, et al. Clutch disc with centrifugal pendulum absorber. Auto Tech Review, 2016, 5(4): 26-31.

[7] G Z Liu, W K Shi, GX Shang. Experimental study on the roar of a passenger car and the torsional vibration of the drive train. Automotive Engineering, 2018, 40(4): 431-433. (in Chinese)

[8] J Jiao. Powertrain torsional vibration of a certain-FR MPV. Hefei: Hefei University of Technology, 2017. (in Chinese)

[9] Y Cai. Research and optimization of torsional vibration characteristics of FR automobile powertrain. Chengdu: Southwest Jiaotong University, 2018. (in Chinese)

[10] F Li, W R Li, D Wang. Simplification method for torsional vibration simulation model of automobile powertrain. Science and Technology Innovation, 2018(6): 179-183. (in Chinese)

[11] L K Yang, HY Li, B Ma. Friction-induced vibration of wet clutches. Journal of Vibration and Shock, 2016, 35(9): 117-122. (in Chinese)

[12] X Liu, W B Shangguan, X Jing, et al. Vibration isolation analysis of clutches based on trouble shooting of vehicle accelerating noise. Journal of Sound \& Vibration, 2016, 382(10): 84-99.

[13] H H Yu, ZTTang. Analysis of the influence of clutch damping on torsional vibration of automobile transmission system. Equipment Manufacturing Technology, 2018(4): 85-87. (in Chinese)

[14] M Zhu. Parameter optimization of automotive powertrain system based on torsional vibration. Chengdu: Southwest Jiaotong University, 2016. (in Chinese)

[15] J S Prasad, N C Damodar, T S Naidu. Clutch hysteresis maximization for elimination of gear rattle in a passenger bus. SAE Technical Paper, 2013-26-0100.

[16] N Tsujiuchi, T Koizumi, N Hara, et al. The effects of clutch damper in idling driveline rattle. Topics in Nonlinear Dynamics, Volume 1: Proceeding of the 31st IMAC, A Conference on Structural Dynamics, 2013, 35: 259-267.

[17] R BH Agate, A Badkas, K Mohan. Driveline torsional analysis and parametric optimization for reducing driveline rattle. SAE 2015-01-2176, 2015.

[18] H W Wu, G Q Wu, X Chen, et al. Design and development of three-stage stiffness clutch damper and its damping performance analysis. Journal of Mechanical Engineering, 2019, 55(4): 75-83. (in Chinese)

[19] X L Liu, W B Shangguan, Q F Hou, et al. Modeling and analysis method of automotive driveline transmission system for reducing gear rattle. Journal of Mechanical Engineering, 2017, 53(4): 85-96. (in Chinese)
[20] S P Fu, S B Li, N Luo, et al. Dynamic optimization of tracked vehicle powertrain based on torsional vibration analysis. Advances in Mechanical Engineering, 2016, 8(5): 1-12.

[21] Bhagate R, Badkas A, Mohan K. Driveline torsional analysis and parametric optimization for reducing driveline rattle. SAE 2015 Noise and Vibration Conference and Exhibition, 2015: 2015-01-2176.

[22] W B Shangguan, T Sun, RY Zheng, et al. Effect of the performance of the driven disc of the friction clutch on vehicle judder during starting. Journal of Vibration Engineering, 2016, 29(3): 488-497.

[23] C Lian. Research on torsional vibration of vehicle driveline. Chongqing: Chongqing University, 2011. (in Chinese)

[24] HW Wu, G Q Wu. Centrifugal pendulum vibration absorber and its application to torsional damper with large angular displacement. Automotive Engineering, 2017, 39(12): 1409-1416, 1471.

[25] K Ding, Z Q Chen, Z J Yang. Research on characteristics of transmission rattle based on rigid-flexible coupling model. Journal of Vibration, Measurement \& Diagnosis, 2016, 36(6): 1129-1135. (in Chinese)

[26] HW Wu, G Q Wu. Modeling of manual transmission gear rattle phenomenon and its impact factors. Journal of Tongji University (Natural Science Edition), 2016, 44(1): 136-145.

[27] W B Shangguan, X L Liu, Y M Yin, et al. Modeling of automotive driveline system for reducing gear rattles. Journal of Sound and Vibration, 2018, 416: 136-153.

[28] H J Yue, Y Zhang, H B Li, et al. Transmission gear vibration mechanism and modification method for vibration and noise reduction. Journal of Beijing University of Aeronautics and Astronautics, 2017, 43(10): 2003-2010.

[29] Ivan R S Gregori, Ivandro Sanches, Carlos EThomaz. Clutch judder classification and prediction: A multivariate statistical analysis based on torque signals. Transaction on Industrial Electronics, 2017, 64(5): 4287-4295.

[30] Alisan Yucesan, Semih Sezer. Vibration isolation with clutch disk predamper mechanism for the idle rattle phenomenon. Journal of Vibration and Control, 2018, 24(8): 1518-1534.

[31] J L Bi, J B Li, et al. Torsional vibration modal and sensitivity analysis of a drive-train system. Journal of Vibration Engineering, 2010, 12: 676-680.

[32] Z F Yan, TS Zhang. Design and manufacture of automobile clutch. Beijing: China Machinery Press, 2018.

\section{Submit your manuscript to a SpringerOpen ${ }^{\circ}$ journal and benefit from:}

- Convenient online submission

- Rigorous peer review

- Open access: articles freely available online

- High visibility within the field

Retaining the copyright to your article

Submit your next manuscript at springeropen.com 